\title{
Role of Alternative Donor Allogeneic Transplants in the Therapy of Acute Myeloid Leukemia
}

\author{
Hany Elmariah, MD, MS, and Keith W. Pratz, MD
}

\begin{abstract}
Adult acute myeloid leukemia (AML) is often associated with a poor prognosis, with allogeneic transplantation representing the greatest chance of cure for eligible patients. Historically, the preferred donor source is a human leukocyte antigen-matched blood relative, although only approximately $30 \%$ of patients have access to such a donor. Alternative donor sources, including matched unrelated donors, umbilical cord blood, and haploidentical related donors, are available for almost every patient and are increasingly being used for patients without a matched related donor. Survival outcomes with these alternative donor sources now approximate those of matched related donor transplants. Given the safety and success of alternative donor transplants, comparative trials are needed to reassess the optimal donor source for patients with AML. This review summarizes the available data on these alternative donor transplants. Further investigation is needed to contemporize donor selection algorithms, but, in the current era, donor availability should no longer preclude a patient's eligibility for an allogeneic blood or marrow transplant.
\end{abstract}

J Natl Compr Canc Netw 2017;15(7):959-966 doi:10.6004/jnccn.2017.0119

\section{Background}

For 40 years, standard therapy for acute myeloid leukemia (AML) has remained infusional cytarabine/ anthracycline-based induction chemotherapy to achieve remission, followed typically by high-dose cytarabine consolidative therapy to prevent relapse. ${ }^{1}$ In patients at high risk of relapse due to advanced age, unfavorable cytogenetics or molecular mutations, AML secondary to an antecedent hematologic malignancy, or relapsed/refractory disease, an allogeneic hematopoietic cell transplant (alloHCT) offers improved survival and the potential for cure. ${ }^{2-6}$ Nonetheless, the effectiveness of this treatment is limited by 2 primary factors: toxicity and donor availability.

Early efforts at alloHCT for hematologic malignancies were associated with extensive treatment-related toxicity, including graft-versus-host disease (GVHD), infection, and organ damage, leading to transplant-related

From the Department of Oncology, Sidney Kimmel Comprehensive Cancer Center at Johns Hopkins, Baltimore, Maryland.

Submitted January 30, 2017; accepted for publication May 2, 2017.

The authors have disclosed that they have no financial interests,

arrangements, affiliations, or commercial interests with the mortality (TRM) rates sometimes exceeding 30\%.,2,7 This is particularly important in AML, which commonly affects older patients who are less tolerant of toxicities. ${ }^{8}$ The safety of alloHCT is dependent on not only the intensity of the conditioning regimen but also the genetic disparity between the donor and recipient. ${ }^{9,10}$ Selection of genetically similar donors limits alloreactivity between the immune systems of the donor and recipient, thus reducing the incidence of GVHD and graft rejection. The most important factor in preventing these immune complications is matching of major histocompatibility antigens, also known as human leukocyte antigens (HLAs), which is determined through molecular-based testing. ${ }^{11-14}$ Of secondary importance are minor histocompatibility antigen mismatches, which can lead to alloreactivity with resultant GVHD and graft rejection, although to a lesser degree than major HLA antigens. ${ }^{15}$ Although testing for minor histocompatibility antigens is not typically prac- manufacturers of any products discussed in this article or their competitors.

Correspondence: Keith W. Pratz, MD, Department of Oncology, Sidney Kimmel Comprehensive Cancer Center at Johns Hopkins, 1650 Orleans Street, CRB 1 Room 2M45, Baltimore, MD 21287. E-mail: kpratz1@jhmi.edu 
ticed, donors who are blood relatives of the recipient are favored as a means to empirically decrease minor histocompatibility mismatch. Based on this rationale, HLA-matched related donors (MRDs) have been the preferred donor source since the advent of alloHCT.

HLA antigens are inherited on the short arm of chromosome 6 and separated into 2 clinically relevant classes: I (HLA A, B, and C) and II (HLA DRB1, DQB1, and DPB1)..$^{14}$ Each antigen is inherited as 2 haplotypes: 1 from the mother and 1 from the father. Because of this pattern of inheritance, a patient is rarely a full match with their parents or children. However, there is a $25 \%$ chance for a pair of siblings to inherit the same haplotypes from both parents. Overall, only 30\% of patients requiring an alloHCT have an available MRD. ${ }^{16}$ Thus, alternative donor sources, including HLA-matched unrelated donors (MUDs), umbilical cord blood transplantation (UCBT), and haploidentical related donors, have become critical to expand the donor pool.

Although alternative donor sources are typically only used when an MRD is unavailable, there are inherent benefits to these genetically disparate donor sources. An alloreactive immune response known as the graft-versus-leukemia (GVL) effect contributes to the therapeutic benefit of an alloHCT. ${ }^{17}$ Clinical evidence has shown that GVL can be boosted with a greater degree of donor:recipient genetic disparity, resulting in lower rates of relapse in high-risk diseases such as AML. ${ }^{17,18}$ Unfortunately, GVL and GVHD are mechanistically similar, so an increase in GVL is generally offset by a concomitant increase in GVHD. Hence, strategies to balance the benefits and toxicities of donor:recipient genetic disparity are essential to the viability of alternative donor sources. Significant progress has been made during the past 40 years, allowing for flexibility in the donor selection process and donor availability for nearly every patient (Table 1). 16,19,20

\section{Alternative Donor Sources}

\section{Matched Unrelated Donors}

Since the early 1980s, registries of volunteer adult donors have been used to locate appropriate MUDs, with $>18$ million donors now registered worldwide. ${ }^{16,21}$ Most patients are able to find a requisite $8 / 8$ HLA matched donor, although there is significant ethnic disparity in this likelihood. For example, in the
United States where the population is ethnically diverse, patients of white European descent have a 75\% chance of finding an MUD, whereas African Americans only have an $18 \%$ likelihood. Other ethnicities fall between these 2 extremes. ${ }^{16}$ The reasons for these discrepancies include both underrepresentation of some ethnic groups in the donor pool and increased genetic variation within certain ethnic populations, making HLA matching inherently less likely.

There is extensive historical experience with MUD transplants showing outcomes approaching MRD transplants, although mostly based on retrospective data. The largest such analysis compared outcomes with MRD versus MUD transplants in 2,223 patients with AML regardless of prior therapy or conditioning. ${ }^{22}$ Acute GVHD risk was much higher in the 8/8 HLA MUD group at 51\% compared with 33\% in the MRD group, although relapse rates (39\% vs 38\%) and overall survival (OS; $35 \%$ vs 34\%) were similar between these groups. Another study compared outcomes using MUDs versus MRDs in 584 patients with AML, although limited to those in first complete remission (CR1). ${ }^{23}$ In this subset, OS and leukemiafree survival (LFS) did not differ statistically between MRD and MUD groups. However, there was a higher risk of chronic GVHD in the MUD group (59\% vs $43 \%$ ), and increased incidence of chronic GVHD correlated with reduced relapse rates.

Although MUDs have proven to be an effective donor source, it should be noted that the outcomes reported are for patients who successfully underwent HCT, thus excluding those for whom a donor was unavailable or who experienced relapse while waiting for a donor to be identified. Identification of a donor often delays HCT by weeks to months, which has been correlated with negative outcomes in patients with AML, such as increased relapse and TRM. ${ }^{24}$ A recent multicenter study using expedited HLA typing to accelerate the search process still resulted in an average wait times of 76 days (range, 20 365 days) from remission to bone marrow transplant (BMT). ${ }^{25}$ Increasing donor availability by allowing for $7 / 8$ or $9 / 10$ HLA matches for unrelated donors has been shown to increase mortality. ${ }^{16,22,26}$

\section{Umbilical Cord Blood Transplant}

In the 1980s, Broxmeyer et $\mathrm{al}^{27}$ discovered that umbilical cord blood (UCB), usually discarded after birth, could potentially be used as a source of 
Alternative Donor BMT for AML

Table 1. Summary of Select Allogenic Transplant Studies Organized by Donor Source

\begin{tabular}{|c|c|c|c|c|c|c|c|c|c|c|c|c|c|c|c|}
\hline $\begin{array}{l}\text { Donor } \\
\text { Source }\end{array}$ & Study & $\begin{array}{c}\text { Total } \\
\text { Patients (N) }\end{array}$ & $\begin{array}{l}\text { Patients With } \\
\text { AML (N) }\end{array}$ & $\begin{array}{l}\text { Follow-Up } \\
\text { Period }\end{array}$ & Conditioning & Graft Type & $\begin{array}{l}\text { Median Age, } \\
\text { y (Range) }\end{array}$ & Engraftment & $\begin{array}{l}\text { Relapse } \\
\text { Rate }\end{array}$ & LFS $^{a}$ & $\mathrm{OS}^{\mathrm{a}}$ & $\begin{array}{l}\text { Acute } \\
\text { GVHD }\end{array}$ & $\begin{array}{l}\text { Severe } \\
\text { Acute } \\
\text { GVHD }\end{array}$ & $\begin{array}{l}\text { Chronic } \\
\text { GVHD }\end{array}$ & TRM \\
\hline \multicolumn{16}{|c|}{ Matched related donor } \\
\hline & Saber et al, ${ }^{22} 2012$ & 624 & 624 & $3 y$ & Any & BM, PBSCT & $52(21-76)$ & $97 \%$ & $39 \%$ & $35 \%$ & $39 \%$ & $33 \%$ & $12 \%$ & $44 \%$ & $25 \%$ \\
\hline & Gupta et al, ${ }_{1}^{23} 2010$ & 226 & 226 & $3 y$ & Any & BM, PBSCT & $40(1-74)$ & N/A & $37 \%$ & $42 \%$ & $45 \%$ & $38 \%$ & $19 \%$ & $43 \%$ & $21 \%$ \\
\hline & $\begin{array}{l}\text { Di Stasi et al, }{ }^{57} \\
2014\end{array}$ & 87 & 58 & $3 y$ & NM & BM, PBSCT & $60(24-76)$ & $99 \%$ & $28 \%$ & $36 \%$ & $\mathrm{~N} / \mathrm{A}$ & $31 \%$ & $11 \%$ & $31 \%$ & $20 \%$ \\
\hline \multicolumn{16}{|c|}{ Matched unrelated donor } \\
\hline & Saber et al, ${ }^{22} 2012$ & 1,193 & 1,193 & $3 y$ & Any & BM, PBSCT & $51(21-75)$ & $95 \%$ & $38 \%$ & $34 \%$ & $37 \%$ & $51 \%$ & $23 \%$ & $48 \%$ & $28 \%$ \\
\hline & Gupta et al, ${ }_{1}^{23} 2010$ & 254 & 254 & $3 y$ & Any & BM, PBSCT & $45(0-73)$ & N/A & $40 \%$ & $34 \%$ & $37 \%$ & $54 \%$ & $25 \%$ & $59 \%$ & $26 \%$ \\
\hline & Rocha et al, ${ }^{33} 2004$ & 584 & 317 & $2 y$ & Myelo & BM & $32(15-59)$ & $89 \%$ & $23 \%$ & $42 \%$ & $42 \%$ & $39 \%$ & $19 \%$ & $46 \%$ & $38 \%$ \\
\hline & Eapen et al, ${ }^{34} 2010$ & 1,360 & 804 & $2 y$ & Myelo & BM, PBSCT & 33,39 & $93 \%-96 \%$ & $33 \%$ & $57 \%$ & $\mathrm{~N} / \mathrm{A}$ & $45 \%$ & $\mathrm{~N} / \mathrm{A}$ & $48 \%$ & $23 \%$ \\
\hline & $\begin{array}{l}\text { Brunstein et } \mathrm{al}_{,}^{41} \\
2012\end{array}$ & 313 & 294 & $2 y$ & RIC & PBSCT & $59(23-69)$ & $98 \%$ & $44 \%$ & $35 \%$ & $44 \%$ & $33 \%$ & $14 \%$ & $56 \%$ & $21 \%$ \\
\hline & $\begin{array}{l}\text { Di Stasi et al, }{ }^{57} \\
2014\end{array}$ & 108 & 71 & $3 y$ & NM & BM, PBSCT & $62(21-76)$ & $96 \%$ & $23 \%$ & $27 \%$ & $\mathrm{~N} / \mathrm{A}$ & $29 \%$ & $6 \%$ & $21 \%$ & $35 \%$ \\
\hline & Ciurea et al 61 & 1,245 & 1,245 & $3 y$ & Myelo & BM, PBSCT & $(21-70)$ & $97 \%$ & $39 \%$ & N/A & $50 \%$ & $33 \%$ & $13 \%$ & $53 \%$ & $20 \%$ \\
\hline & 2015 & 737 & 737 & $3 y$ & NM & BM, PBSCT & $(21-70)$ & $96 \%$ & $42 \%$ & N/A & $44 \%$ & $28 \%$ & $11 \%$ & $52 \%$ & $23 \%$ \\
\hline & $\begin{array}{l}\text { Milano et al, } \\
2016\end{array}$ & 344 & 175 & $4 y$ & Myelo & BM, PBSCT & $40(1-67)$ & N/A & $24 \%$ & N/A & $63 \%$ & N/A & $14 \%$ & N/A & $17 \%$ \\
\hline \multicolumn{16}{|c|}{ Umbilical cord blood transplantation } \\
\hline & $\begin{array}{l}\text { Laughlin et al, } \\
2001\end{array}$ & 68 & 19 & $2 y$ & Myelo & Single UCBT & $31.4(17-58)$ & $90 \%$ & N/A & $26 \%$ & $40 \%$ & $60 \%$ & $20 \%$ & $36 \%$ & $47 \%$ \\
\hline & Rocha et al,,332004 & 98 & 45 & $2 y$ & Myelo & Single UCBT & $24.5(15-55)$ & $75 \%$ & $23 \%$ & $32 \%$ & $36 \%$ & $26 \%$ & $13 \%$ & $30 \%$ & $44 \%$ \\
\hline & Eapen et al, ${ }^{34} 2010$ & 165 & 76 & $2 y$ & Myelo & Single UCBT & 28 & $80 \%$ & $26 \%$ & $59 \%$ & $\mathrm{~N} / \mathrm{A}$ & $30 \%$ & $\mathrm{~N} / \mathrm{A}$ & $24 \%$ & $33 \%$ \\
\hline & $\begin{array}{l}\text { Barker et al, } \\
2005\end{array}$ & 23 & 13 & $1 \mathrm{y}$ & Myelo & $\begin{array}{l}\text { Double } \\
\text { UCBT }\end{array}$ & $24(13-53)$ & $100 \%$ & N/A & $57 \%$ & $61 \%$ & $65 \%$ & $13 \%$ & $23 \%$ & $22 \%$ \\
\hline & $\begin{array}{l}\text { Milano et al, } \\
2016\end{array}$ & 140 & 73 & $4 y$ & Myelo & $\begin{array}{l}\text { Double } \\
\text { UCBT }\end{array}$ & $29(1-64)$ & $\mathrm{N} / \mathrm{A}$ & $15 \%$ & N/A & $71 \%$ & N/A & $18 \%$ & N/A & $18 \%$ \\
\hline & $\begin{array}{l}\text { Brunstein et al }{ }^{41} \\
2012\end{array}$ & 121 & 99 & $2 y$ & TCF & $\begin{array}{l}\text { Double } \\
\text { UCBT }\end{array}$ & $55(23-68)$ & $93 \%$ & $49 \%$ & $31 \%$ & $37 \%$ & $50 \%$ & $17 \%$ & $34 \%$ & $19 \%$ \\
\hline & $\begin{array}{l}\text { Brunstein et al, }{ }^{59} \\
2011\end{array}$ & 50 & 29 & $1 \mathrm{y}$ & NM & $\begin{array}{l}\text { Double } \\
\text { UCBT }\end{array}$ & $58(16-69)$ & $90 \%$ & $31 \%$ & $46 \%$ & $54 \%$ & $40 \%$ & $21 \%$ & $25 \%$ & $24 \%$ \\
\hline \multicolumn{16}{|c|}{ Haploidentical } \\
\hline & $\begin{array}{l}\text { Aversa et al, }{ }^{47} \\
1998\end{array}$ & 43 & 20 & $1.5 \mathrm{y}$ & Myelo & TCD-PBSCT & $22(4-53)$ & $95 \%$ & $10 \%$ & $36 \%$ & $28 \%$ & $0 \%$ & $0 \%$ & $0 \%$ & $40 \%$ \\
\hline & Aversa et al, ${ }^{48} 2005$ & 104 & 67 & $2 y$ & Myelo & TCD-PBSCT & $33(9-64)$ & $93 \%$ & $24 \%$ & $37 \%$ & $\mathrm{~N} / \mathrm{A}$ & $8 \%$ & $2 \%$ & $7 \%$ & $37 \%$ \\
\hline & Luznik et al, ${ }^{55} 2008$ & 68 & 27 & $2 y$ & NM with PTCy & BM & $46(1-71)$ & $87 \%$ & $58 \%$ & $26 \%$ & $36 \%$ & $34 \%$ & $6 \%$ & $7 \%$ & $15 \%$ \\
\hline & $\begin{array}{l}\text { McCurdy et al, } \\
2015\end{array}$ & 372 & 120 & $3 y$ & NM with PTCy & BM & $55(18-75)$ & $90 \%$ & $46 \%$ & $40 \%$ & $50 \%$ & $32 \%$ & $4 \%$ & $13 \%$ & $11 \%$ \\
\hline & $\begin{array}{l}\text { Di Stasi et al, }{ }^{57} \\
2014\end{array}$ & 32 & 22 & $3 y$ & NM with PTCy & BM, PBSCT & $52(20-67)$ & $97 \%$ & $33 \%$ & $30 \%$ & $\mathrm{~N} / \mathrm{A}$ & $29 \%$ & $0 \%$ & $11 \%$ & $24 \%$ \\
\hline & $\begin{array}{l}\text { Brunstein et al, }{ }^{59} \\
2011\end{array}$ & 50 & 22 & $1 \mathrm{y}$ & NM with PTCy & BM & $48(7-70)$ & $98 \%$ & $45 \%$ & $48 \%$ & $62 \%$ & $32 \%$ & $0 \%$ & $13 \%$ & $7 \%$ \\
\hline & $\begin{array}{l}\text { Huang et al }, 53 \\
2006\end{array}$ & 171 & 51 & $2 y$ & GIAC & $\mathrm{BM}+\mathrm{PBSCT}$ & $23(2-56)$ & $100 \%$ & $12 \%$ & $68 \%$ & $\mathrm{~N} / \mathrm{A}$ & $55 \%$ & $23 \%$ & $74 \%$ & $20 \%$ \\
\hline & Cieri et al, ${ }^{60} 2015$ & 40 & 22 & $1 \mathrm{y}$ & $\begin{array}{l}\text { Myelo with } \\
\text { PTCy }\end{array}$ & PBSCT & $55(27-78)$ & $100 \%$ & $41 \%$ & $48 \%$ & $56 \%$ & $15 \%$ & $8 \%$ & $20 \%$ & $17 \%$ \\
\hline \multirow{2}{*}{\multicolumn{2}{|c|}{$\begin{array}{l}\text { Ciurea et al, }{ }^{, 1} \\
2015\end{array}$}} & 104 & 104 & $3 y$ & $\begin{array}{l}\text { Myelo with } \\
\text { PTCy }\end{array}$ & BM, PBSCT & $(21-70)$ & $90 \%$ & $44 \%$ & N/A & $45 \%$ & $16 \%$ & $7 \%$ & $30 \%$ & $14 \%$ \\
\hline & & 88 & 88 & $3 y$ & NM with PTCy & $\mathrm{BM}, \mathrm{PBSCT}$ & $(21-70)$ & $93 \%$ & $58 \%$ & N/A & $46 \%$ & $19 \%$ & $2 \%$ & $34 \%$ & $9 \%$ \\
\hline
\end{tabular}

aPer follow-up period.

Abbreviations: AML, acute myloid leukemia; BM, bone marrow; GVHD, graft-versus-host disease; LFS, leukemia-free survival; Myelo, myeloablative; N/A, not applicable; NM, nonmyeloablative; OS, overall survival; PBSCT, peripheral blood stem cell transplantation; PTCy, posttransplant cyclophosphamide; RIC, reduced-intensity conditioning; TCD, T-cell depleted; TCF, total body irradiation $200 \mathrm{cGy}$ + cyclophosphamide + fludarabine; TRM, transplant-related mortality; UCBT, umbilical cord blood transplant. 
hematopoietic stem cells for transplantation. Soon after, Gluckman et $\mathrm{al}^{28}$ performed the first UCBT in a human, successfully curing a patient with Fanconi anemia. After initial success with related donor UCBTs, the New York Blood Center established the Placental Blood Program as a novel source of unrelated transplants in $1992 .{ }^{29}$ The feasibility of UCBTs has been bolstered by subsequent data showing that these products can be stored and used for $>20$ years. ${ }^{30}$ Additionally, because the immune system of UCB is immature, it is acceptable to use cords that are only 4/6 HLA matches (HLA A, B, and DRB1). ${ }^{31}$ This flexibility has been tremendously important, with $>90 \%$ of patients, including minorities, able to find appropriate MUDs or UCB. ${ }^{16}$

A landmark multicenter study published in 2001 prospectively evaluated myeloablative UCBT in 68 adult patients with hematologic malignancies, including 19 with AML. ${ }^{32}$ Long-term LFS was achieved in 26\% of patients, with severe acute GVHD in 20\% and chronic GVHD in 38\% of long-term survivors. Although promising, toxicities including infection and end-organ injury resulted in 47\% TRM. Large retrospective studies were subsequently published comparing UCBT with MUD transplants. In Europe, an analysis was performed evaluating outcomes of 682 patients with acute leukemia, 362 of whom had AML, after myeloablative transplants. Results showed an OS rate of $36 \%$ in the UCBT group versus $44 \%$ in the MUD group, and TRM of $44 \%$ for UCBT compared with 38\% for MUDs. Engraftment and acute GVHD were significantly lower in the UCBT group ( $75 \%$ vs $89 \%$, and $26 \%$ vs $39 \%$, respectively). ${ }^{33}$ More recently, similar results were reported in a study comparing myeloablative UCBTs with MUDs (both marrow and peripheral blood donors) in 1,525 adult patients, 880 of whom underwent transplant for AML. ${ }^{34}$ This study reinforced the efficacy of UCBT, with long-term LFS and OS rates that were comparable to the MUD groups at nearly $50 \%$, and with significantly lower rates of both acute and chronic GVHD. However, TRM in the UCB group remained high at $37 \%$ compared with approximately $23 \%$ in the MUD groups, and only $80 \%$ achieved neutrophil recovery compared with $>90 \%$ after MUD transplant.

Many early studies on UCBTs demonstrated that TRM and engraftment were improved when the donated cord had a higher total nucleated cell dose and CD34-positive cell dose. ${ }^{32,35}$ To increase the total nucleated cell dose, investigators at the University of Minnesota developed a novel approach using myeloablative conditioning with 2 partially matched (4-6/6 HLA) UCBTs given to the same patient sequentially. ${ }^{36}$ All 21 patients engrafted and, by day 100 , hematopoiesis from a single cord predominated in every patient. Severe acute GVHD rates were low at only $13 \%$, suggesting safety of the method. Single versus double cord transplants have not been compared extensively in adults, but prospective trials in children (including young adults) have demonstrated similar survival, although a higher risk of GVHD, when using double cord transplants. ${ }^{37,38}$ Milano et $\mathrm{al}^{39}$ retrospectively compared outcomes using this double cord technique versus MUD transplants in $582 \mathrm{pa}$ tients with acute leukemia or myelodysplastic syndromes (MDS). The relapse rate in the UCBT group was $15 \%$ compared with $24 \%$ in the MUD group. This difference proved to be significant specifically in patients with minimal residual disease, suggesting that double UCBTs may have a superior GVL effect over MUDs. As an alternative to double UCBTs, efforts to expand cell count ex vivo are ongoing and have demonstrated promising early results. ${ }^{40}$

Given the toxicity reported in myeloablative UCBT trials and the advanced age of many patients with AML, nonmyeloablative conditioning has been studied to make UCBT safer. The largest such study retrospectively compared nonmyeloablative UCBT versus MUD and mismatched unrelated donors in 585 patients ( 523 with AML). TRM, OS, and LFS in the UCBT group were 19\%, 37\%, and $31 \%$, respectively, all within the statistical error of the MUD group. Risks of acute GVHD were higher with UCBT compared with MUD, although chronic GVHD was lower in the UCBT group. ${ }^{41}$ Additionally, nonmyeloablation results in efficient and robust immune reconstitution, even in older patients who are known to have slower reconstitution due to thymic atrophy or toxicity. ${ }^{42}$

UCBT has helped expand the donor pool to almost all patients requiring a transplant, but has been associated with relatively high rates of TRM. Optimization of many variables, such as cell dose and conditioning regimen, continues to improve outcomes. In particular, in the nonmyeloablative setting, UCBT may be particularly safe and effective. Additionally, UCBTs are readily available and may 
be preferred when the risk of relapse precludes an extended MUD search.

\section{Haploidentical Related Transplants}

Because HLA genes are inherited as 2 haplotypes (one set from each parent), any patient will, by definition, match his parents and children for at least 1 haplotype. ${ }^{43}$ Additionally, a sibling has a $75 \%$ chance of being at least a haploidentical match. Thus, almost all patients have at least 1 haploidentical donor, and most have multiple. This high frequency of readily available donors allows for rapid donor selection without a costly and prolonged unrelated donor search.

Early transplants using haploidentical donors were poorly tolerated due to immense alloreactivity created by HLA mismatch, resulting in high rates of graft failure, GVHD, and mortality. ${ }^{11,13,44}$ Because these toxicities are mediated by $T$ cells, selective ex vivo T-cell depletion (TCD) of the graft has been attempted to improve donor:recipient immune tolerance. Initial studies of this technique yielded low GVHD rates but high rates of treatment failure. ${ }^{45,46}$ Noting that high stem cell doses seemed to improve outcomes, Aversa et $\mathrm{al}^{47}$ implemented a strategy of using granulocyte colony-stimulating factor (GCSF)-stimulated peripheral blood stem cells with ex vivo TCD, resulting in an infusion of mega-doses of CD34-positive stem cells. Conditioning included myeloablation and antithymocyte globulin, and no posttransplant immunosuppression was used. In a phase II study of 101 patients with acute leukemia (67 with AML), primary engraftment was successful in $93 \%$, both chronic and acute GVHD occurred in $<10 \%$, and relapse occurred in $24 \%$ of those with AML. ${ }^{48}$ Nonetheless, feasibility was limited by a TRM of $40 \%$ due largely to infectious complications. Research is ongoing to improve outcomes for TCD haploidentical HCTs by depleting or reinfusing select T-cell populations to bolster immune reconstitution, although results have been mixed and longterm feasibility is unclear. ${ }^{49-52}$

The Peking University Institute of Hematology group $^{53}$ developed an alternative myeloablative regimen with GCSF stimulation of the donor, intensified immunosuppression including antithymocyte globulin, and a combined peripheral blood stem cell and bone marrow graft, commonly called the GIAC strategy. This initial study included 171 patients, 51 of whom had AML. Severe acute and chronic GVHD rates were 23\% and 74\%, respectively. The nonrelapse mortality (NRM) rate was $20 \%$, with a relapse rate of only $12 \%$, although this included patients with low-risk disease. For patients with higher-risk disease, the NRM rate increased to $31 \%$, with a relapse rate of $39 \%$. A subsequent multicenter prospective study comparing this regimen in patients with AML yielded similar results, while also confirming that the outcomes were nearly equivalent to those in the MRD arm. ${ }^{54}$

Investigators at the Sidney Kimmel Comprehensive Cancer Center at Johns Hopkins later developed a haploidentical HCT regimen to target alloreactive $\mathrm{T}$ cells in vivo using nonmyeloablative conditioning, a bone marrow stem cell source, and posttransplant cyclophosphamide (PTCy) at $50 \mathrm{mg} / \mathrm{kg}$ on days 3 and 4 after transplantation followed by oral immunosuppresion..$^{55}$ Rate of initial engraftment, severe acute GVHD, and chronic GVHD rates were favorable at $87 \%, 6 \%$, and $5 \%$, respectively, although the relapse rate was high at $51 \%$. The safety and feasibility of the PTCy regimen have been replicated in multiple subsequent studies. ${ }^{56-58}$

A few studies have compared nonmyeloablative PTCy haploidentical HCTs to other donor sources. A retrospective study compared outcomes of 227 patients with AML or MDS undergoing HCT with either MRD, MUD, or haploidentical donors using the PTCy regimen. ${ }^{57}$ Engraftment in the haploidentical group was $97 \%$. Haploidentical patients experienced no severe acute GVHD, which was significantly better than $11 \%$ in the MRD group. Otherwise, NRM and relapse rates were comparable across the 3 groups. Although no published trials have directly compared PTCy haploidentical HCTs to UCBTs, results of parallel multicenter phase II studies of patients with leukemia or lymphoma suggested that the haploidentical group had lower rates of NRM (7\% vs $24 \%$ ) but higher rates of relapse ( $45 \%$ vs $31 \%$ ). ${ }^{59}$

To help decrease relapse rates, some investigators have used myeloablative conditioning with PTCy. A more recent prospective study used a treosulfanmelphalan myeloablative regimen before haploidentical peripheral blood stem cell transplants with PTCy. ${ }^{60}$ The overall relapse rate was 35\% and NRM rate was still favorable at $17 \%$ at 1 year. A large retrospective study compared PTCy haploidentical versus MUD transplants in 1,982 adult patients with AML, allowing for both nonmyeloablative and 
myeloablative conditioning. ${ }^{61}$ OS was comparable for both haploidentical and MUD donor groups at $44 \%$ to $50 \%$, regardless of conditioning. Acute and chronic GVHD rates were significantly lower in the haploidentical group for both myeloablative and nonmyeloablative conditioning. For the myeloablative groups, NRM rates were 14\% after haploidentical and 20\% after MUD transplants, whereas relapse rates were $44 \%$ and $39 \%$ after haploidentical and MUD transplants, respectively.

Overall, haploidentical HCT offers an alternative to matched donor transplants that is easily accessible, has lower donor acquisition costs, and is safe. The primary weakness of this modality may be higher reported relapse rates, which counteract the survival benefits otherwise gained by low TRM. Myeloablative conditioning may better balance toxicity and long-term efficacy, although further investigation is needed. Regardless, overall outcomes appear comparable to matched donor sources.

\section{Discussion}

BMT remains the only curative therapy for high-risk AML. The ability to offer transplantation was previously limited by MRD availability, but with donor options described herein, nearly every patient now has a viable donor option. Because of lack of prospective comparative data and seemingly similar OS with all alternative donor sources, institutions vary in terms of their donor preferences. Our institutional practice is to prioritize transplants on study protocols to evaluate these questions.

As evidenced in the studies summarized herein, haploidentical HCTs result in extremely low rates of GVHD and favorable TRM compared with MUDs, but higher rates of relapse. However, because these studies compare only patients who successfully underwent transplant, they do not account for those who became ineligible for transplant while waiting to locate a donor. Indeed, one European study of patients with AML showed that average time to MUD HCT was 4.4 months for those successfully transplanted, resulting in 30\% of patients becoming medically unfit for transplant while awaiting a donor. ${ }^{62}$ Comparatively, with haploidentical transplants, rapid donor identification allows for transplantation at the time when patients would routinely be getting the first course of consolidation. If these differences are considered, haploidentical outcomes may prove superior to MUDs.

Like haploidentical transplants, UCBTs are readily available and can often be obtained in $<1$ month. ${ }^{63}$ Compared with haploidentical HCTs, UCBTs confer lower rates of relapse. However, haploidentical HCTs result in superior toxicity profile and low TRM. Additionally, haploidentical HCTs allow the option of giving donor lymphocyte infusions to treat relapse after HCT, which is not possible after UCBTs. A prospective, multicenter, comparative trial (ClinicalTrials.gov identifier: NCT01597778) is ongoing to help determine, decisively, if one of these donor sources is superior.

Lastly, the success of alternative donor sources highlights the fact that it is reasonable to choose an alternative donor over an MRD when other factors favor the alternative donor. For example, recent data demonstrated that older MRDs may be unfavorable due to increasing risk of clonal hematopoiesis with age resulting in worse survival after transplant. ${ }^{64,65}$ Other donor-related factors known to influence transplant outcomes, such as comorbidities, cytomegalovirus status, blood type, killer-cell immunoglobulin-like receptor type, and sex may also be considered. Future studies should investigate whether such variables should take precedence over donor match.

\section{Conclusions}

High-risk AML is a devastating hematologic malignancy characterized by a poor prognosis. Allogeneic HCT can be curative in approximately $40 \%$ of patients who are able to undergo the procedure. One of the historical barriers to success, donor availability, should no longer be a limitation. Alternative donor sources, including MUDs, UCB, and haploidentical related donors, are available for nearly all patients with AML. Outcomes with these donors now approximate those of MRD transplants. Comparative trials are needed to reassess the optimal donor source for patients with AML because prioritizing HLA match may no longer be necessary. Further investigation is needed to assess the impact non-HLA variables have on HCT outcomes, which may better guide donor selection. 


\section{References}

1. Döhner H, Estey E, Amadori S, et al. Diagnosis and management of acute myeloid leukemia in adults: recommendations from an international expert panel, on behalf of the European LeukemiaNet. Blood 2010;115:453.

2. Yanada M, Matsuo K, Emi N, Naoe T. Efficacy of allogeneic hematopoietic stem cell transplantation depends on cytogenetic risk for acute myeloid leukemia in first disease remission: a metaanalysis. Cancer 2005;103:16521658.

3. Koreth J, Schlenk R, Kopecky K, et al. Allogeneic stem cell transplantation for acute myeloid leukemia in first complete remission: systematic review and meta-analysis of prospective clinical trials. JAMA 2009;301:23492361.

4. Burnett A, Goldstone A, Hills R, et al. Curability of patients with acute myeloid leukemia who did not undergo transplantation in first remission. J Clin Oncol 2013;31:1293-1301.

5. Rashidi A, Ebadi M, Colditz G, DiPersio J. Outcomes of allogeneic stem cell transplantation in elderly patients with acute myeloid leukemia: a systematic review and meta-analysis. Biol Blood Marrow Transplant 2016;22:651-657.

6. Prébet T, Gore SD, Esterni B, et al. Outcome of high-risk myelodysplastic syndrome after azacitidine treatment failure. J Clin Oncol 2011;29:33223327.

7. Burnett A, Wheatley K, Goldstone A, et al. The value of allogeneic bone marrow transplant in patients with acute myeloid leukaemia at differing risk of relapse: results of the UK MRC AML 10 trial. Br J Hematol 2002;118:385-400.

8. Dores G, Devesa S, Curtis R, et al. Acute leukemia incidence and patient survival among children and adults in the United States, 2001-2007. Blood 2012;119:34-43.

9. Diaconescu R, Flowers C, Storer B, et al. Morbidity and mortality with nonmyeloablative compared with myeloablative conditioning before hematopoietic cell transplantation from HLA-matched related donors. Blood 2004;104:1550-1558.

10. Champlin R, Khouri I, Anderlini P, et al. Nonmyeloablative preparative regimens for allogeneic hematopoietic transplantation. Nature 2001;27(Suppl 2):S13-22.

11. Anasetti C, Amos D, Beatty PG, et al. Effect of HLA compatibility on engraftment of bone marrow transplants in patients with leukemia or lymphoma. New Engl J Med 1987;320:197-204.

12. Clift R, Hansen J, Thomas E, et al. Marrow transplantation from donors other than HLA-identical siblings. Transplantation 1979;28:235-242.

13. Beatty $P$, Clift R, Mickelson E, et al. Marrow transplantation from related donors other than HLA-identical siblings. N Engl J Med 1985;313:765771.

14. Eng H, Leffell M. Histocompatibility testing after fifty years of transplantation. J Immunol Methods 2011;369:1-21.

15. Bonnet D, Warren E, Greenberg P, et al. CD8(+) minor histocompatibility antigen-specific cytotoxic $\mathrm{T}$ lymphocyte clones eliminate human acute myeloid leukemia stem cells. Proc Natl Acad Sci U S A 1999;96:8639_ 8644.

16. Grager L, Eapen M, Williams E, et al. HLA match likelihoods for hematopoietic stem-cell grafts in the U.S. registry. $N$ Engl J Med 2014;371:339-348.

17. Horowitz M, Gale R, Sondel P, et al. Graft-versus-leukemia reactions after bone marrow transplantation. Blood 1990;75:555-562.

18. Gale R, Horowitz M, Ash R, et al. Identical-twin bone marrow transplants for leukemia. Ann Intern Med 1994;120:646-652.

19. Spellman S, Eapen M, Logan B, et al. A perspective on the selection of unrelated donors and cord blood units for transplantation. Blood 2012;120:259-265.

20. Bray R, Hurley C, Kamani N, et al. National marrow donor program HLA matching guidelines for unrelated adult donor hematopoietic cell transplants. Biol Blood Marrow Transplant 2008;14:45-53.

21. Lown $R$, Shaw B. Beating the odds: factors implicated in the speed and availability of unrelated haematopoietic cell donor provision. Bone Marrow Transplant 2013;48:210-219.

22. Saber W, Opie S, Rizzo J, et al. Outcomes after matched unrelated donor versus identical sibling hematopoietic cell transplantation in adults with acute myelogenous leukemia. Blood 2012;119:3908-3916.

23. Gupta V, Tallman M, He W, et al. Comparable survival after HLA-wellmatched unrelated or matched sibling donor transplantation for acute myeloid leukemia in first remission with unfavorable cytogenetics at diagnosis. Blood 2010;116:1839-1848.
24. Frassoni F, Labopin M, Powles R, et al. Effect of centre on outcome of bone-marrow transplantation for acute myeloid leukaemia. Lancet 2000;355:1393-1398.

25. Page J, Othus M, Garcia-Manero G, et al. Feasibility of allogeneic hematopoietic cell transplantation among high-risk AML patients in first complete remission: results of the transplant objective from the SWOG (S1203) randomized phase III study of induction therapy using standard $7+3$ therapy or idarubicin with high-dose cytarabine (IA) versus IA plus vorinostat [abstract]. Presented at the 58th ASH Annual Meeting \& Exposition; December 3-6, 2016; San Diego, California. Abstract 1166.

26. Lee $S$, Klein J, Haagenson M, et al. High-resolution donor-recipient HLA matching contributes to the success of unrelated donor marrow transplantation. Blood 2007;110:4576-4583.

27. Broxmeyer H, Douglas G, Hangoc G, et al. Human umbilical cord blood as a potential source of transplantable hematopoietic stem/progenitor cells. Proc Natl Acad Sci U S A 1989;86:3828-3832.

28. Gluckman E, Broxmeyer $H$, Auerbach A, et al. Hematopoietic reconstitution in a patient with Fanconi's anemia by means of umbilicalcord blood from an HLA-identical sibling. N Engl J Med 1989;321:11741178.

29. Kurtzberg J, Laughlin M, Graham M, et al. Placental blood as a source of hematopoietic stem cells for transplantation into unrelated recipients. $\mathrm{N}$ Engl J Med 1996;355:157-166.

30. Broxmeyer H, Lee M, Hangoc G, et al. Hematopoietic stem/progenitor cells, generation of induced pluripotent stem cells, and isolation of endothelial progenitors from 21- to 23.5-year cryopreserved cord blood. Blood 2011;117:4773-4777.

31. Eapen M, Rubinstein P, Zhang M, et al. Outcomes of transplantation of unrelated donor umbilical cord blood and bone marrow in children with acute leukaemia: a comparison study. Lancet 2007;369:1947-1954.

32. Laughlin M, Barker J, Bambach B, et al. Hematopoietic engraftment and survival in adult recipients of umbilical-cord blood from unrelated donors. N Engl J Med 2001;344:1815-1822.

33. Rocha V, Labopin M, Sanz G, et al. Transplants of umbilical-cord blood or bone marrow from unrelated donors in adults with acute leukemia. N Engl J Med 2004;351:2276-2285.

34. Eapen M, Rocha V, Sanz G, et al. Effect of graft source on unrelated donor haemopoietic stem-cell transplantation in adults with acute leukaemia: a retrospective analysis. Lancet Oncol 2010;11:653-660.

35. Wagner J, Barker J, DeFor T, et al. Transplantation of unrelated donor umbilical cord blood in 102 patients with malignant and nonmalignant diseases: influence of CD34 cell dose and HLA disparity on treatmentrelated mortality and survival. Blood 2002;100:1611-1618.

36. Barker J, Weisdorf D, DeFor T, et al. Transplantation of 2 partially HLAmatched umbilical cord blood units to enhance engraftment in adults with hematologic malignancy. Blood 2005;105:1343-1347.

37. Michel G, Galambrun C, Sirvent A, et al. Single- vs double-unit cord blood transplantation for children and young adults with acute leukemia or myelodysplastic syndrome. Blood 2016;127:3450-3457.

38. Wagner J, Eapen M, Carter S, et al. One-unit versus two-unit cord-blood transplantation for hematologic cancers. N Engl J Med 2014;371:16851694.

39. Milano F, Gooley T, Wood B, et al. Cord-blood transplantation in patients with minimal residual disease. N Engl J Med 2016;375:944-953.

40. deLima M, McNiece I, Robinson S, et al. Cord-blood engraftment with ex vivo mesenchymal-cell coculture. N Engl J Med 2012;367:2305-2315.

41. Brunstein C, Eapen $M$, Ahn $K$, et al. Reduced-intensity conditioning transplantation in acute leukemia: the effect of source of unrelated donor stem cells on outcomes. Blood 2012;119:5591-5598.

42. Chao N, Liu C, Rooney B, et al. Nonmyeloablative regimen preserves "niches" allowing for peripheral expansion of donor T-cells. Biol Bone Marrow Tranplant 2002;8:249-256.

43. Kanakry C, Fuchs E, Luznik L. Modern approaches to HLA-haploidentical blood or marrow transplantation. Nat Rev Clin Oncol 2016;13:10-24.

44. Szydlo R, Goldman J, Klein J, et al. Results of allogeneic bone marrow transplants for leukemia using donors other than HLA-identical siblings. J Clin Oncol 1997;15:1767-1777.

45. Reisner Y, Kirkpatrick D, Dupont B, et al. Transplantation for acute leukaemia with HLA-A and B nonidentical parental marrow cells fractionated with soybean agglutinin and sheep red blood cells. Lancet 1981;318:327-331.

46. Ash R, Horowitz M, Gale R, et al. Bone marrow transplantation from related donors other than HLA-identical siblings: effect of T cell depletion. Bone Marrow Transplant 1991;7:443-452. 
47. Aversa F, Tabilio A, Velardi A, et al. Treatment of high-risk acute leukemia with T-cell-depleted stem cells from related donors with one fully mismatched HLA haplotype. N Engl J Med 1998;339:1186-1193.

48. Aversa F, Terenzi A, Tabilio A, et al. Full haplotype-mismatched hematopoietic stem-cell transplantation: a phase II study in patients with acute leukemia at high risk of relapse. J Clin Oncol 2005;23:3447-3454.

49. Bethge $W$, Faul $C$, Bornhäuser $M$, et al. Haploidentical allogeneic hematopoietic cell transplantation in adults using CD3/CD19 depletion and reduced intensity conditioning: an update. Blood Cells Mol Dis 2008;40:13-19.

50. Airoldi I, Bertaina A, Prigione I, et al. $\gamma \delta$ T-cell reconstitution after HLAhaploidentical hematopoietic transplantation depleted of TCR- $\alpha \beta+$ CD19+. Blood 2015;125:2349-2358.

51. Perruccio K, Tosti A, Burchielli E, et al. Transferring functional immune responses to pathogens after haploidentical hematopoietic transplantation. Blood 2005;106:4397-4406.

52. Martelli M, Dilanni M, Ruggeri L, et al. "Designed" grafts for HLAhaploidentical stem cell transplantation. Blood 2014;123:967-973.

53. Huang X, Liu D, Liu K, et al. Haploidentical hematopoietic stem cell transplantation without in vitro T-cell depletion for the treatment of hematological malignancies. Bone Marrow Transplant 2006;38:291-297.

54. Wang Y, Liu Q, Xu L, et al. Haploidentical vs identical-sibling transplant for AML in remission: a multicenter, prospective study. Blood 2015;125:3956-3962.

55. Luznik L, O'Donnell P, Symons H, et al. HLA-haploidentical bone marrow transplantation for hematologic malignancies using nonmyeloablative conditioning and high-dose, posttransplantation cyclophosphamide. Biol Blood Marrow Transplant 2008;14:641-650.

56. McCurdy S, Kanakry J, Showel M, et al. Risk-stratified outcomes of nonmyeloablative HLA-haploidentical BMT with high-dose posttransplantation cyclophosphamide. Blood 2015;125:3024-3031.

57. Di Stasi A, Milton DR, Poon LM, et al. Similar transplantation outcomes for acute myeloid leukemia and myelodysplastic syndrome patients with haploidentical versus 10/10 human leukocyte antigen-matched unrelated and related Donors. Biol Blood Marrow Transplant 2014;20:1975-1981.

58. Kasamon Y, Bolaños-Meade J, Prince G, et al. Outcomes of nonmyeloablative HLA-haploidentical blood or marrow transplantation with high-dose post-transplantation cyclophosphamide in older adults. J Clin Oncol 20015;33:3152-3161.

59. Brunstein C, Fuchs E, Carter S, et al. Alternative donor transplantation after reduced intensity conditioning: results of parallel phase 2 trials using partially HLA-mismatched related bone marrow or unrelated double umbilical cord blood grafts. Blood 2011;118:282-288.

60. Cieri N, Greco R, Crucitti L, et al. Post-transplantation cyclophosphamide and sirolimus after haploidentical hematopoietic stem cell transplantation using a treosulfan-based myeloablative conditioning and peripheral blood stem cells. Biol Blood Marrow Transplant 2015;21:1506-1514.

61. Ciurea S, Zhang M, Bacigalupo A, et al. Haploidentical transplant with post-transplant cyclophosphamide versus matched unrelated donor transplant for acute myeloid leukemia. Blood 2015;126:1033-1040.

62. Heemskerk M, vanWalraven S, Cornelissen J, et al. How to improve the search for an unrelated haematopoietic stem cell donor. Faster is better than more! Bone Marrow Transplant 2005;35:645-652.

63. Barker J, Krepski $\mathrm{T}$, DeFor $\mathrm{T}$, et al. Searching for unrelated dono hematopoietic stem cells: availability and speed of umbilical cord blood versus bone marrow. Biol Blood Marrow Transplant 2002;8:257.

64. Gibson C, Kennedy J, Nikiforow S, et al. Donor chip causes donor-derived clonal hematopoiesis as an early complication of allogeneic stem cell transplantation [abstract]. Presented at the 58th ASH Annual Meeting \& Exposition; December 3-6, 2016; San Diego, California. Abstract 987.

65. Kröger $\mathrm{N}$, Zabelina $\mathrm{T}$, deWreede $\mathrm{L}$, et al. Allogeneic stem cell transplantation for older advanced MDS patients: improved survival with young unrelated donor in comparison with HLA-identical siblings. Leukemia 2013;27:604-609.

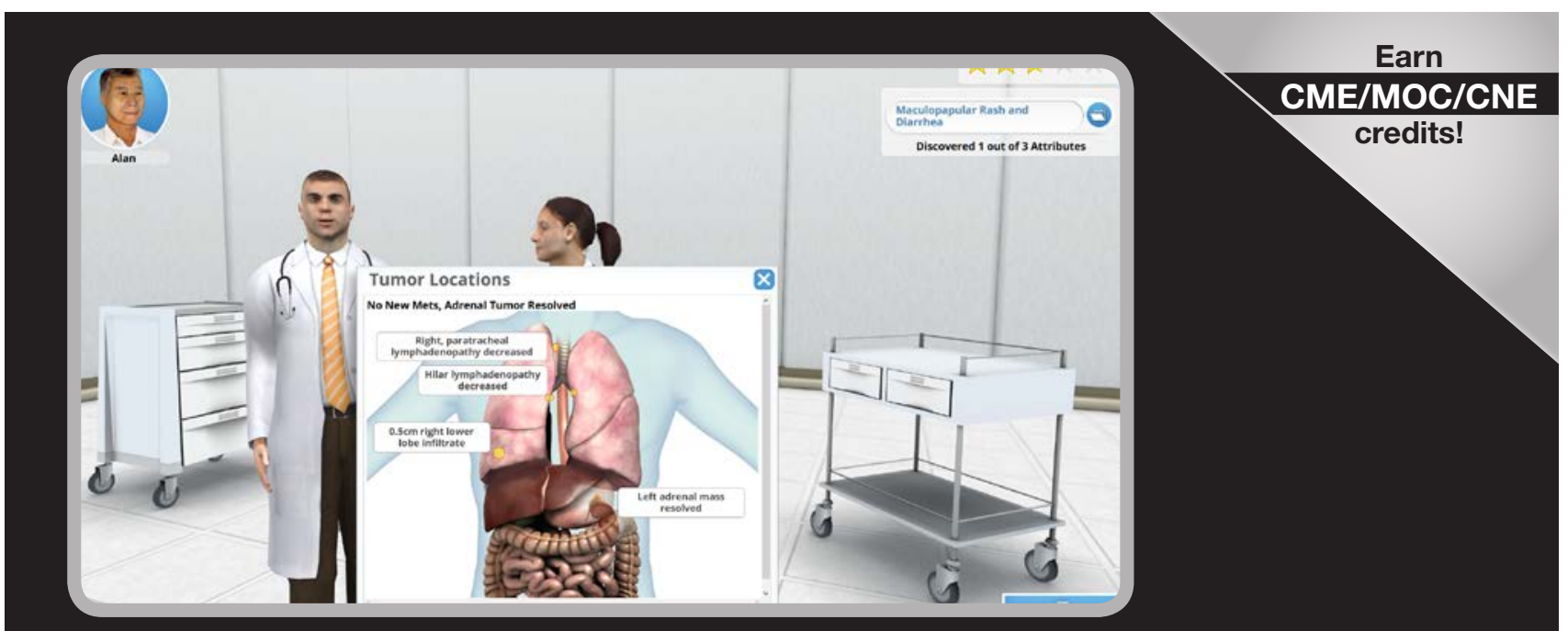

ADVANCED NON-SMALL CELL LUNG CANCER PATIENT MANAGEMENT SIMULATOR

Brought to you by the National Comprehensive Cancer Network ${ }^{\circledR}$ (NCCN ${ }^{\circledR}$ ) Powered by Syandus Simulation Technology

education.nccn.org/nsclc-simulator



